\title{
4. Adapting to circumstance: the 2001 Census in the Alice Springs town camps
}

\section{Will Sanders}

\section{Introduction}

The Australian national census of population and housing is conducted every five years by the ABS. It attempts to collect basic demographic and socioeconomic information about the total Australian population and various subsets of that population, such as Indigenous Australians. As Indigenous Australians are a small minority of all Australians whose circumstances can differ considerably from those of the majority population, the ABS has over recent censuses adopted a special enumeration strategy for Indigenous Australians, particularly in the discrete Indigenous communities in sparsely settled northern and central Australia. The elements of this IES have been in place in the Northern Territory since 1976, Western Australia and South Australia since 1981 and in Queensland since 1991 (see Taylor 1993, and this volume; Loveday \& Wade-Marshall 1985). They involve special Indigenous household and personal questionnaires which are designed for interview-based completion, rather than the self-completion of a single household questionnaire relied on in the larger population. Interviewers, or census collectors, are often recruited through Indigenous organisations and are usually themselves Indigenous. CCs, who oversee interviewers, are also recruited through contact with Indigenous community organisations and may also be Indigenous. CCs also undertake work on a third special Indigenous form, the Dwelling Check List, for each discrete Indigenous community.

Through the IES an attempt has clearly been made by the ABS to work in consultation and cooperation with local Indigenous organisations and individuals, as well as to develop a questionnaire procedure which is more appropriate to the circumstances of those being counted. Despite these efforts, doubts about the adequacy of census information relating to Indigenous Australians have continued to be raised. Indigenous community organisations have frequently suggested, when presented with census figures, that their community has been under-enumerated. Researchers too have had cause to suggest under enumeration and other data inadequacies (see for example Taylor 1993, Martin \& Taylor 1995). As a result, it seemed useful to attempt to observe the conduct of the 2001 Census in some of these discrete Indigenous communities where the special enumeration strategy was to be used. This paper reports on the conduct of the 2001 Census in the Aboriginal town camps of Alice Springs.

\section{Background}

The town camps of Alice Springs provide a living space for Aboriginal people which is considerably different from general suburban housing. At their least developed, the camps can be a series of officially-unrecognised improvised humpies. Nowadays, however, most 
camps are considerably more developed and recognised than this, with some security of land tenure, some community facilities such as running water, lighting and ablution blocks and some more formally constructed dwellings, be they perhaps only basic tin sheds. At their most developed, the Alice Springs town camps have some of the characteristics of low-cost residential housing estates, with toilets and other facilities in individual houses, a clear block and road layout and house numbers, if not street names.

The town camps in Alice Springs have been assisted in their development over the last 25 years by the Tangentyere Council, an Aboriginal organisation specifically established for this purpose. Tangentyere now services and assists 19 town camps which are spread across Alice Springs, predominantly on its outskirts but also in some instances in small areas nearer the centre of town (see Fig 4.1).

The ABS approached Tangentyere during the first half of 2001 seeking its cooperation and assistance in the conduct of the census in the Alice Springs town camps. The initial reaction from Tangentyere was not very positive. Past censuses had not been particularly useful to Tangentyere. They had not identified the town camps as distinct collection districts (CDs) and so little or no information could be extracted from past censuses relating specifically to the town camps. Tangentyere's reaction became more positive when it was explained to them by the ABS's central Australian census manager that CDs in Alice Springs for the 2001 census had been re-designed so as to separate out the town camps. Eleven identifiable CDs covered the 19 town camps serviced by Tangentyere, some covering only one town camp and some covering two or three town camps close together in a particular area of town (see Fig. 4.1).

Tangentyere agreed to do what it could to assist the ABS with the conduct of the census. It undertook to provide the ABS with the list of dwellings in the town camps for which it attempted to charge rent in order to help with the construction of Dwelling Check Lists for the 19 town camps. It also undertook to provide a training room and to provide ABS with access to a pool of potential local Aboriginal workers through its Job Shop and general networks. It was also agreed that two Tangentyere staff members from the housing section would be dedicated full time for two weeks to the census collection process on a cost recovery basis. All this was arranged while the central Australian census manager, a permanent ABS employee, was still based in Darwin,1,600 kilometres to the north, there being no permanent ABS office in central Australia.

\section{Getting going}

The ABS's central Australian census manager arrived in Alice Springs in mid June 2001 and began gearing up the operation. The plan for the discrete Aboriginal communities, both in Alice Springs and out bush, was to conduct the census over a period of perhaps two or three weeks in the month before the official census day on 7 August. The intention was to avoid the complication of a major movement of people from these communities to the Yuendumu Sports Weekend on 4-6 August. A related aim was to enumerate people over a period of time in a fairly usual place of residence, rather than just somewhere they happened to be visiting on a particular night. 
Fig.4.1 Alice Springs Community Living Areas, with hand annotations of town camp CD numbers

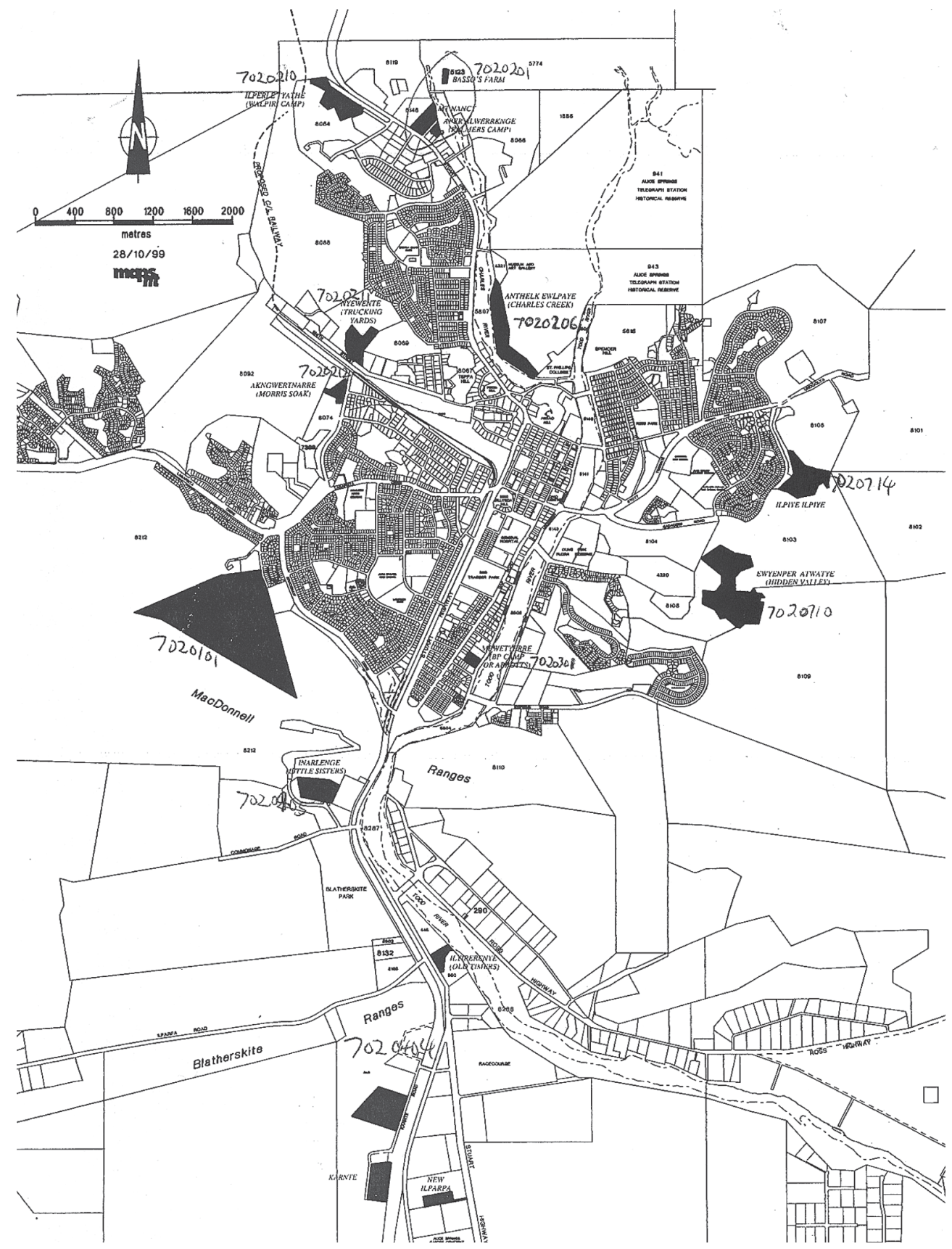

Source: NT Department of Lands / Maps NT 
The time-frame of this plan began gradually to change when it proved somewhat more difficult to recruit interviewer-collectors (henceforth interviewers) and CCs for the town camps than had first been anticipated. Four potential CCs had been identified by the ABS's central Australian census manager in conjunction with Tangentyere, two of whom were the Tangentyere housing employees, one of whom was an ex-Tangentyere employee now working with another Aboriginal organisation in town, and one of whom was a former long-term Department of Social Security officer. All were, at least partly, of Aboriginal descent and were well known in the area. At an initial strategy meeting and training session for CCs organised for 7 July, only one of the four turned up, along with the Tangentyere housing manager. At a second training session organised for $20 \mathrm{July}$, only the two who were not employees of Tangentyere showed up and it was soon ascertained that the two Tangentyere employees had decided they could not combine census collection with their current employment responsibilities relating to housing work.

This training session went well, with both coordinators clearly catching on quickly to the nature of the task they were being asked to undertake. One indicated that he was somewhat restricted in the time he could devote to the job, because of his employment elsewhere. But the other was not otherwise employed and had more time at his disposal. Both were asked to try and find other Aboriginal people who might be interested in being interviewers and a number of possible times for an interviewer training session were identified a week to ten days hence. It was also decided that the central Australian census manager should try to meet the Tangentyere Executive Council the following week to try to build some more support within Tangentyere for the census collection process now that it was imminent.

As well as hoping that the two CCs would be able to come up with Aboriginal people who might be interested in being interviewers, the central Australian census manager also put in some time over the next week encouraging the Tangentyere Job Shop to refer people on to him. An interviewer training session was finally organised for 31 July and five potential interviewers and the two CCs attended. This training session went for three to four hours. All the participants seemed interested and to be picking up the idea of the work quite quickly, but the training was as yet incomplete as none had themselves practiced filling in actual census forms. The training session was called to a halt around 1.30 p.m. as the seven participants all felt they had had enough for one day, and a continuation of the session was organised for the next morning. Only three of the five newly-recruited potential interviewers showed up the next day to complete the training, together with one of the two CCs. All went well, although there were some interesting issues raised during the process of practising filling out forms. These are worthy of further discussion so they can be revisited in the light of actual collection experience.

Starting with the SIHF, the central Australian census manager emphasised that the ABS in the Northern Territory was trying to enumerate primarily on a usual residence basis in these discrete Aboriginal communities. This meant, he explained, that all people who had lived in a dwelling in a community for more than six months of the previous year or were likely to live there for more than six months of the next year could be counted as 'people who live here', the language the SIHF used to describe usual residents (see 
Appendix B). He also noted that visitors or 'people who are staying here' should also be listed on the SIHF, but that if they were also likely to be counted elsewhere they did not need a SIPF filled out for them. Some visitors would require a SIPF, but some would not. The count, on the SIPFs, was thus to be usual residents plus some visitors, though all visitors present were to be listed on the SIHFs. This seemed reasonably clear and well understood.

A little further on in discussion of the SIHF, it was suggested by one or two of the trainees that it might be difficult to get a figure for the rent paid for the house from any one individual interviewee, as the Tangentyere rent policy was partly a per person contribution scheme and not just a single, clear per house rent. It was suggested that perhaps the rental information should be obtained direct from Tangentyere, rather than from the interviewees and that this could tie in with the construction of the Dwelling Check Lists. As noted above, the Dwelling Check Lists which were being drawn up for the town camps were derived from Tangentyere's administrative records and covered any dwelling for which Tangentyere was attempting to collect some rent.

There was also some discussion of the issue of age and the fact that some Aboriginal people might not know their age precisely. It was however agreed that they might know their year of birth, from which age could be calculated, but that if they did not, an estimate of age could be made from discussing with them other people and events.

Another question which caused some concern was the income question (Q. 28, see Appendix C) on the SIPF. It was felt that the distinction between before and after tax would not be made and some people may say what they get weekly, as Tangentyere CDEP employees are paid weekly, and that a quick calculation would need to be made. Some of the concern about this question was allayed when the collectors realised that they did not have to obtain precise income figures, but merely had to place people in pre-determined categories. Some discussion ensued as to which of these income categories people on various Centrelink payments and CDEP would probably be in.

Another question which caused comment, rather than concern, was whether the person had looked for a job in the last four weeks. It was generally agreed that not many of the people in the town camps would be actively looking for work, as there was not much work around that they had any chance of obtaining, but that they would probably say they were looking for work if they were on Newstart Payments because that was what the conditions of payment required them to say when asked that question by Centrelink.

At the end of this second morning of training it was agreed that the three collectors and one CC were ready to start. It was agreed for all to meet the next morning at nine o' clock at a particular small town camp and to 'have a go' before the people there started moving around for the day. It was generally agreed that early morning was going to be the best time of day to get people in the camps because of movement out of the camps to other places in town later in the day and also because of drinking going on in the camps later in the day. 
The next day, Thursday 2 August, only two of the three fully-trained interviewers turned up at the small town camp for the first collection, and the third never returned. There was at that point no Dwelling Check List for this camp, as there were no dwellings there for which Tangentyere was attempting to collect rent. The CC set about constructing a Dwelling Check List by looking around. There were five tin sheds without internal services and two sets of communal ablution blocks and toilets. Meanwhile one of the interviewers had approached one of the tin sheds and was beginning to complete a SIHF for it. A 'Person $l^{\prime}$ was identified, somewhat arbitrarily, and others who had obviously spent the previous night sleeping in or around that tin shed were gradually added. Others, who had not so obviously slept in or around this tin shed the previous night but perhaps somewhere else around the camp, also came over and offered their names. Soon the SIHF contained a list of 14 people, and the interviewer and $\mathrm{CC}$ realised that it was perhaps becoming more of a communal personal checklist. The CC and the interviewer decided to abandon the idea of separate households in this small camp and just to work on this one SIHF. At that point, after about 15 minutes' work, the addition of people to this single SIHF was halted and attention was switched to filling out SIPFs for the 14 people now listed on the form.

Both interviewers now worked on the filling in of SIPFs for these 14 people for about two hours, while the CC, who did not himself fill out SIPFs, provided support by calling people back to have their forms done and fielding questions about how answers to questions should be treated; for example what sorts of training courses qualified for a 'yes' answer in the post-school education questions, since many of these people had over the years undertaken some training course or another. By 11.15 a.m. SIPFs had been completed for 12 of the 14 people on the single SIHF, while the other two, it was indicated, had 'walked away' from the camp to do something else. One of the collectors, who lived at an adjacent town camp, agreed to come back at another time to try and track down these two. The people at the camp had begun to lose interest in the census collection process and no more were offering themselves to be put on either the existing single SIHF or on a new one. The interviewers too were tired and they did not actively try to identify and pursue any other individuals who might still be in the camp but not on the first SIHF. The CC and the interviewers agreed to adjourn for the day and the two interviewers agreed that they would continue on their own in other camps with which they were familiar the next day.

During that first morning's work I had, as an observer, noted 25 people in that camp at about 9.15 a.m. When I mentioned this to the central Australian census manager, he in turn mentioned it to the $\mathrm{CC}$ who replied that it had been ascertained that the other people in the camp that morning were just visitors and therefore did not need to be counted. If the principles enunciated in training had been followed, these visitors would of course have been listed on SIHFs and then divided into those who did and those who did not require a SIPF depending on whether they were likely to be counted elsewhere. But in practice, with the overall collection task proving somewhat time consuming and arduous, the idea of someone being a visitor was used by interviewers and the $\mathrm{CC}$ as a rationale for not listing them even on a SIHF, thereby reducing the task at hand to slightly more manageable proportions. The emphasis was, after all, as they had been told in training, on counting people where they are usual residents. 
We will return to these issues later. But as an observer of the collection at that first camp that first day, I should perhaps say that I was not entirely convinced by the line of argument that the other 11 people in the camp that morning were visitors. I had observed some discussion about particular people who were present that morning not 'belonging' there. However, from the way this was said I had interpreted it to mean as much that they were not particularly welcome at the camp, as that they did not usually live there or were not currently staying there. Indeed, it seemed likely that the forceful assertion of their not 'belonging' probably reflected the fact that they had stayed there a while, uninvited, and were likely to continue doing so for some time to come. The likelihood of their being counted elsewhere in the census was at least questionable. And the census had now been done in this camp, except for the issue of returning to get SIPFs for the last two people on the single SIHF.

\section{Twelve days in August: building the effort}

On Friday 3 August, I accompanied one of the two fully-trained and now practicallyexperienced interviewers to another town camp to begin the count there. This was a more developed camp with a block and street layout and houses numbered from one up into the twenties, but no street names. We approached one of the houses which had people visibly in and around it that morning and the collector asked for the person whose name was listed against this house on the Dwelling Check List derived from the Tangentyere housing list. It was quickly ascertained that this person no longer lived there and that others had taken over. A middle-aged man offered himself as household spokesperson and, through that process, became nominated as 'Person 1' for the SIHF. Once more, there followed a 15-minute process of adding household members' names, genders, ages and relationships to a SIHF. What emerged was an extended family household of middle-aged brothers and sisters and their partners, and a more elderly father of those brothers and sisters. There were no children physically evident at the household and an inquiry about this elicited the response that the children were back in communities out bush. This was largely an adults' place for town-based living, including a fair bit of drinking, although clearly the links with communities and children out bush were quite strong and frequent. Indeed while we were there a taxi load of five more people arrived at the house, complete with blankets and including two children. Also one of the adults present offered the information that he and some others were that afternoon heading out to Yuendumu for the sports weekend and that they might not be back for a while.

Once the initial process of filling out the SIHF had been completed, attention turned once again to filling out SIPFs. Four were completed within an hour and before people started wandering off and doing other things for the day. By 10.15 a.m. the collector was having trouble getting those listed on the SIHF to sit with him and do a SIPF. They had contributed to the filling in of the SIHF, watched two or three people do SIPFs and were now losing interest in the process. The interviewer too was getting tired and did not want to have to push people. We adjourned from the camp for a break and for the interviewer to buy some more cigarettes. He had just given away half a packet as a part of the process of interesting people in the census collection process! 
When I adjourned to my office I wrote the following in my field journal:

It strikes me that the most problematic part of this collection process is keeping up the interest of the respondents and, to a lesser extent, the collectors. This interviewer, who is good, got half a household done this morning before he and they needed a break. At that rate, with only two interviewers up and running at this stage, this census could take months. The likely result is a very significant undercount as people just avoided putting themselves forward to the collectors, or simply never come in contact with them.

I wondered whether SIPFs would ever be obtained for the six other people in that morning's dwelling who had been listed on the SIHF, since some were now heading off to Yuendumu, and whether the family that had arrived in the taxi with their blankets would ever be counted. They were now staying at a house where, like the small camp of the day before, the census had for all intents and purposes largely been done, though there were still SIPFs for that household which needed to be filled out.

The central Australian census manager was, at this stage of proceedings, very much aware that he needed to get more interviewers working in the town camps. He had initially been aiming for between eight and ten interviewers, on the assumption that they could each complete between 100 and 200 forms over a two or three week period and thus potentially together count somewhere between 1,000 and 1,500 people in the Alice Springs town camps. Tangentyere had over recent years attempted some very basic counts of its own which had indicated a town camp population of between 800 and 1,300 and this had formed the basis for the census manager's approach. However the initial recruitment and training drive had not yielded anything like this number of interviewers. Another attempt would have to be made.

At this point, the attention of the central Australian census manager was fairly fully taken up with the upcoming conduct of the larger, more general census only four days away. He did, however, manage to recruit three more potential interviewers through the Tangentyere Job Shop and conduct a training session for them on census day itself, Tuesday 7 August. Although I did not attend this training session, I did on that day have further contact with the census interviewer that I had observed in action the previous Thursday and Friday. He reported that he had 'not done all that much' as he had had a few personal issues to deal with. He had also clearly been somewhat discouraged by the experience of working on his own, as he suggested to me that it had been better working in a team, like he and the other interviewer and the $\mathrm{CC}$ had done on the Thursday morning. He intended checking in with the central Australian census manager in the next day or so, but was clearly finding the work pretty tough going.

The day after census day I met again with the central Australian census manager and a team of people from Tangentyere whom he had put together to do the homeless count in Alice Springs on census night. Although the team was drawn from Tangentyere, that night's work focused on places outside the 19 formally recognised town camps. It was intended to enumerate people who were sleeping rough that night, in places like the Todd River bed, which runs through the middle of Alice Springs and provides a convenient 
sitting place for Aboriginal people during the day and sometimes a sleeping place at night. This homeless enumeration appeared to have gone quite smoothly. It involved only a single short personal form with nine fairly straightforward questions (see Appendix D). So maintaining the interest and attention of numerous individuals over an extended period of time through both SIHFs and SIPFs was not an issue. For the interviewee, this was a quick, individualised one or two minute process, while for the interviewer it was simply a process of dealing quickly with one individual at a time and then moving on to find the next. The homeless persons census process enumerated 115 people in the Alice Springs area that night, all of whom identified themselves as Aboriginal.

While the central Australian census manager was clearly very pleased with the way the homeless persons census procedure had worked out, he was equally clearly quite worried about how the town camp enumeration procedure was going. He was aware that the original two interviewers had not done all that much and that the three he had trained on 7 August were only just getting going. He set about recruiting some more interviewers, including one who had helped with the homeless census and found it easy, and organising yet another training session, while also trying to provide some more support for the five interviewers and two CCs who were actually out there working.

On Thursday 9 August another training session was held for three new potential interviewers. Two were retained to the end of the training session and then taken into the camps under the supervision of the two CCs on Friday 10 August. Collection in the camps, with seven interviewers, continued over the weekend of 11-12 August and on 13 August a meeting was held at Tangentyere to see how they were all going. Some were clearly finding the work hard and were in danger of losing interest. A quick survey of the work that had been done produced the estimate that somewhat less than 100 people had actually been enumerated in the town camps in the 12 days since 2 August. There was still a long way to go. The collection effort in the town camps had been built up to the sort of level that the central Australian census manager had initially envisaged. But the census manager was still clearly worried that he was not going to be able to sustain the interest and effort of this group of interviewers and CCs for the two or three weeks that were still necessary for completing the collection in all the town camps. A decision point was looming.

\section{The decision to focus on household forms}

Largely by chance a discussion occurred on 13 August between the central Australian census manager and a senior member of the Tangentyere staff about how the census collection was progressing. As an observer who knew both these people, I was both privy to this discussion and a minor participant in it. It was quickly agreed that the current collection process was proving too arduous and was unlikely to be carried through to completion in the next two or three weeks. There was a danger of burning out the interviewers and the CCs, as well as the individuals being interviewed, before the task was done. A suggestion emerged: focusing first and foremost on the SIHFs would ensure that at least a basic enumeration would be completed. 
The central Australian census manager decided to run this idea past his superior in Darwin. Within a couple of days a decision had been made, essentially to follow this course of action. Four columns were to be added manually to the SIHF for the recording of information relating to what Aboriginal language the person spoke, what the standard of their spoken English was, whether they were on CDEP, and whether they were of Aboriginal origin. Interviewers could then transfer these and the other basic data items from the enhanced SIHF to SIPFs in their own time away from the interviewees. This way the interviewers would be paid for the completion of the SIPFs, without the full SIPF process jeopardising the basic enumeration.

On Thursday 16 August another meeting was held at Tangentyere to see how things were going and to inform interviewers and CCs of this revised approach. Two interviewers had by this time fallen by the wayside due to the arduousness of the work, without having done much collecting. Two other interviewers had by the time of this meeting completed enumerations in a single town camp with which they were familiar, but were at this stage either unable or unwilling to take on further work. One of these was one of the two original interviewers, an older woman who was a senior resident of the town camp she had enumerated. She had worked diligently at the census collection task in this one town camp over a two-week period and now had other things to attend to in her life, including a funeral to organise. The other, a younger woman who did not live in the town camp she was enumerating, had informally recruited her father, a Tangentyere employee, to help her with the enumeration and together they had managed to do one camp in three days. But this was clearly more than enough for her.

So there were, in fact, only three interviewers who were available and willing to carry on collecting after this revised enumeration procedure had been devised. Yet the job at this stage was probably still less than half done. Two of these three remaining interviewers worked with one CC and one with the other. The team of three was quickly converted to the new collection procedure and conducted the census in three more town camps over the week of 17-24 August, filling out enhanced SIHFs in the camps and SIPFs elsewhere later. The lone interviewer working with the other CC was less keen on the idea of filling out forms away from people and so persisted with the original collection procedure during this week. He was, however, clearly a very competent collector with more stamina for the work than many of the others, so this was not necessarily a problem.

In the final week of 24-31 August, perhaps one-quarter of the census collection task in the Alice Springs town camps still remained to be done. But the two interviewers working with the one CC had by now had enough. One had domestic issues with which he had been dealing all along, which required him to move house, while the other simply lost interest. The two CCs and the one remaining interviewer all became interviewers and all began using the revised collection methodology. This was necessary just in order to get the job done by 31 August, when the actual census day on 7 August was for most people becoming a quite distant memory and the central Australian census manager was returning to Darwin.

The census collection in the Alice Springs town camps had, in essence, taken the whole of July to initiate and the whole of August to carry out. About 25 people had been 
suggested as possible interviewers, but only ten commenced training. Only seven completed training and commenced interviewing and only five lasted beyond the first few interviews, one of these only for three days and with the informal support and assistance of her father. A major change in procedure had been made half way through the collection period because only about 20 per cent of the work had by then been done. Even with this change in procedure, all but one of the interviewers was burnt out before the end of the process and the CCs were obliged to take on the role of interviewers just in order to get the job finished. Eventually about 980 people were enumerated in 190 dwellings in the Alice Springs town camps, over half of whom were enumerated using the revised collection procedure.

\section{Analysis and policy implications for census collection}

The foregoing account of the 2001 Census collection procedure in the Alice Springs town camps is fairly detailed because it raises some quite fundamental analytical issues for the IES, both as planned and as implemented. The implications for census collection policy in discrete Aboriginal communities like the Alice Springs town camps are quite profound and need to be discussed under a number of separate headings.

\section{Demands and interest: the failure of the two-form structure}

One major issue for analysis relates to how much the special enumeration strategy for the census demands of Aboriginal people as both interviewers and interviewees. The Alice Springs town camp experience in 2001 suggests that the strategy demands far too much of both interviewers and interviewees. The SIHF and SIPF structure is cumbersome and time consuming, and greatly extends the time that both interviewers and interviewees have to dedicate to the task. There is a constant danger that interviewers and interviewees will lose interest in the process before the enumeration is complete. People who have seen others being interviewed, or have other things to attend to, may not offer themselves for interview, while interviewers may burn out after doing just a few households.

To maintain the interest of both interviewers and interviewees the ABS probably needs to develop a simple single-form interview procedure which can be administered quickly. This single form structure could either be an enhanced household form, not unlike the one devised informally half way through the 2001 Alice Springs town camp enumeration process, or a simple personal form, not unlike the special short form used in the homeless enumeration (see Appendix D). The choice between these two single form structures would depend, to some extent, on whether the ABS sees the census as primarily concerned with enumerating and identifying the characteristics of individuals or of households. This is, of course, not entirely an either/or choice. A personal form could ask where people lived, how many other people lived there and whether the interviewee was related to those others, while a household form will inevitably collect some pieces of personal information. But it seems, on the basis of the Alice Springs town camp experience in 2001 that a personal form should be designed to be completed in no more than five minutes and a household 
form, for perhaps ten people, in no more than half to three-quarters of an hour. Otherwise momentum and interest — and people — will be lost.

Under the current two-form structure, by contrast, the enumeration of a household of ten can take up to two and a half hours, with people identified on the SIHF at the beginning expected to hang around for later completion of a SIPF. This is simply too much to ask and the count suffers as a result, through both interviewer burn out and interviewee avoidance.

Considerable thought would need to be given as to which single form structure, and associated personal or household collection emphasis, should be applied to discrete Aboriginal communities in sparsely settled northern and central Australia.

\section{A worst-case scenario?}

In the course of undertaking these observations, it was often suggested to me by the central Australian census manager that census collection in the Alice Springs town camps could, in many ways, be seen as something of a worst-case scenario. There is clearly a very high degree of mobility between the camps and the outlying Aboriginal communities. A good deal of drinking goes on in the camps, which makes collection difficult and at times unpleasant. The daily mobility of town camp residents out of the camps into other areas of Alice Springs is also a problem, making people hard to catch in the dwellings. The spread of the camps across town also makes travel to and from them, or between them, difficult for interviewers.

Despite all these worst-case characteristics, it seems to me that there are also aspects of the Alice Springs town camp situation that are very positive and helpful. Tangentyere is a wellestablished, cooperative, and able Indigenous organisation which cooperated well with the ABS. The interviewers recruited through Tangentyere's Job Shop and its general networks were also of high quality, being people who had through their past employment and other experience considerable exposure to non-Indigenous bureaucratic ways. On these latter counts, the situation in some remote Indigenous communities could be more challenging than in the Alice Springs town camps, with less well-established community organisations and less bureaucratically-experienced individuals on whom to draw as interviewers.

\section{Usual residents or people present: who should be enumerated?}

One further characteristic of the IES as implemented in the Alice Springs town camps was its emphasis on enumerating people who are usual residents of dwellings, plus visitors who were unlikely to be enumerated elsewhere. This is somewhat different from standard census practice, which is to enumerate people present on the night the census, plus absent usual residents who are unlikely to be enumerated elsewhere.

Formally, the IES strategy followed the standard census approach. This was reflected in the SIHF, which asked interviewers to list all people who live in the dwelling 'most of the time' including those who are 'away' and also all visitors. The SIHF then asked the interviewers to divide these people into those who needed a SIPF (i.e. to be enumerated here) and those who did not. And the accompanying training manual explained as follows: 
All people need a Personal Form EXCEPT if they are away in a city, town, another community. If someone is away fishing, hunting, on sorry business, etc., you still need to complete a Personal Form for this person.

The emphasis here was on identifying absent usual residents who would be counted elsewhere and hence did not need to be counted here, to avoid double counting. But all people present, including visitors, were to be counted on SIPFs.

Informally, the Northern Territory census administration had tried to move more to a usual residents basis of enumeration, counting all usual residents including those absent. Visitors were only to be counted if it seemed likely that they would not be counted elsewhere as usual residents. In practice this seemed to mean that interviewers let visitors go, either not recording them at all, even on the SIHFs, or not filling in SIPFs for them.

This seemed to me a highly unsatisfactory resolution of the issue of who should be counted. People present were not being counted on the premise that they would be counted elsewhere as absent usual residents. However, this assumption seemed suspect on a number of counts. First, would they still be recognised as usual residents of a dwelling elsewhere, perhaps out in a bush community, if they had not been there for a while? Second, if they were recognised as absent usual residents somewhere else, would a SIPF be filled in for them? I had observed some willingness to put people not present on the list of household members for the SIHF, but a reluctance to fill in a SIPF for other than oneself. The personalised 'you' language of the SIPF seemed to encourage this reluctance. Third, and specifically in relation to the town camps, it was arguably just as important to count the population present as it was to count those who identified themselves as usual residents.

I would suggest that the Northern Territory census administration's attempt to move to a 'usual residents' basis for enumeration was somewhat half-baked and that in the Alice Springs town camps it probably allowed a lot of visitors, who might not in fact have been counted elsewhere, to slip through the census net. There seem to me to be very good arguments for sticking with the standard census procedure of enumerating people where census collectors encounter them, plus asking those present if there are other absent usual residents. Those present can be asked whether they are usual residents or visitors and if the latter, where their usual residence is. Those absent can be reasonably clearly divided into those who are likely to be enumerated elsewhere and those who are not. But visitors are extremely difficult to divide into those who are likely to be enumerated elsewhere and those who are not. To let the visitors go when they are encountered, on the assumption that others elsewhere will be asked about them and will answer for them, seems perverse. Surely the best source of information about a person is that person.

\section{Time extension and the interview process: an underlying issue}

The attempt by the Northern Territory census administration to move to a usual residents basis of enumeration for discrete Aboriginal communities is, I think, linked to the underlying issue of the time extension of census collection under the IES. 
Standard census enumeration aims for a very short time extension to the count, enumerating people where they sleep on a single night. This can only really be accomplished if most of the count is done by self-enumeration. Where the count is done by interview, the time extension is inevitably going to be greater. Time extension, combined with mobility of the population, introduces a new source of possible counting error: missing people or encountering them more than once as they and the census collectors move around over time. Hence the drive towards identifying usual residents and discounting visitors. However, the significance of error due to time extension and mobility can be overstated. Error is reduced if one counts those present at the time of enumeration and asks, among other things, whether they have been counted elsewhere recently. There may still be underenumeration due to missing some people altogether through mobility, but questions about absent usual residents can pick up on this too. Time extension does not need to entail a switch to a usual residents basis of enumeration. Enumeration can still be of those present, plus absent usual residents. The question that needs to be asked in a time extended census is not who slept in this dwelling on the night of 7 August or some other specific date, but who slept in this dwelling last night. In this way in a time extended census all dwellings get a census night, even if it is not quite the same census night as the dwelling next door or that in another community.

\section{Individual questions: the issue of social relevance}

In relation to individual questions, like those which caused concern for collectors and CCs in the initial training course, the following comments can be made. These all reflect, in one way or another, on what might be referred to as the social relevance of these questions to people living in discrete Aboriginal communities in sparsely settled northern and central Australia.

The attempt to get rent figures for houses from Tangentyere was unsuccessful. Although Tangentyere knew how much rent it collected in total from town camps, it did not allocate this rent definitively to individual houses. Tangentyere collects rent from individuals under a policy which is in fact more like an informal income tax regime, specifying that individuals with particular levels and types of employment and income will be required to contribute certain levels of payment. Some interviewers did obtain a rent figure for the dwellings they enumerated. How these relate to Tangentyere's rent policy and compare with its administrative figures for total rent collection will be interesting to see. The comparison may be a quite useful check on data quality, showing either that the information recorded accords generally with Tangentyere administrative records or that it is somewhat at odds with those records.

The age question did indeed often initially stop people in their tracks. But when rephrased in terms like 'well, in what year were you born?', it often then elicited an answer. I did however witness one miscalculation by ten years from the year of birth back to the actual age. So perhaps an ability to record the raw answer of the year of birth given may be useful. Or, as Morphy (this volume) suggests, an ability just to put people in five or ten year age groupings.

The income question appeared to cause no great problems, though there did seem to be little if any attention paid to the 'before tax' qualification. Figures quoted were most 
frequently fortnightly social security payment amounts, but were sometimes weekly CDEP pays which could be fairly easily doubled up and put into a broad income category.

Question 37 on the SIPF about whether the person had looked for work in the last four weeks did indeed often elicit the equivocation suggested. Some people were inclined to say 'no' at first, suggesting there wasn't any appropriate work around for them. But then they did wonder whether they were supposed to say 'yes', like on Newstart payment forms. In many ways the distinction between being unemployed and not being in the labour force, which this and subsequent questions try to construct, is of little if any social relevance in discrete Aboriginal communities in sparsely settled northern and central Australia. A person in these communities is either employed or they are not. So the line of questioning is a little bit socially irrelevant and nonsensical.

A couple of other questions which caused confusion also deserve to be commented on. Question 5 on the SIPF, the first that actually needed to be asked, caused confusion. It asked whether the person being interviewed was 'more closely related to anyone else here in this house' than person 1 . The relationship between the person being interviewed and person 1 had been established in Q. 4-a question which did not in fact need to be answered, but had been information transferred from the SIHF. Clearly Q. 4 had to be revisited and the answer to it re-identified, if Q. 5 was to make any sense. However, even if this was done, Q. 5 still did not work very well, as there was not necessarily one single other person in the house to whom the person was more closely related. Is a spouse, a child, a parent, or a sibling one's closest relation? Or are they all contenders for that claim?

The question on ancestry (Q. 13) on the SIPF also confused people as it seemed in this context simply to repeat Q. 10 on Aboriginal or Torres Strait Islander origin. Question 10 itself was handled quite well, but like others where the answer was obvious, such as Q. 11 and Q. 12 on whether your mother and father were born in Australia, it was often handled in a joking manner. A joking approach to questions because of their obviousness was common, and was legitimated by the use of this technique in the training video for interviewers.

Question 23 on post-school education, as noted above, often elicited various responses about low level training courses which people had undertaken. This then tied people into answering four more questions about the name of the course, what it involved, the institution at which it was studied and the year it was completed. Whether this was the sort of information that these questions were intended to elicit, again raises the issue of the social relevance of some standard questions to the circumstances of Aboriginal Australians in discrete communities in sparsely settled northern and central Australia.

\section{The Indigenous Enumeration Strategy: how special, how successful, how necessary?}

I want to conclude this analysis by briefly addressing three related questions about the IES. How special, how successful and how necessary is it?

At one level, the IES does indeed seem quite special. It relies on interview rather than selfcompletion, on a separate two-form structure rather than the standard single household form 
and it is time extended, over a month rather than focused on a single day. However, the questions on the special Indigenous forms suggest a reluctance to move away from the standard questions and information sought on the standard household form. The standard household form and its standard questions seeking standard information have simply been broken up into a series of forms and questions with slightly more personalised language, asking in the SIPF about 'you' rather than 'the person' and dealing with each person individually for each question rather than all people in the household together for each question as in the standard household form.

This is arguably a 'worst of both worlds' solution to the challenge of devising an appropriate census collection methodology for Indigenous Australians in discrete communities in sparsely settled northern and central Australia. The content of the census remains standard, but the collection process actually becomes more complex and elaborate. Interviewers are asked to coordinate SIHFs and SIPFs through person numbers, as well as record numbers, and to transfer items of information between SIHFs and SIPFs. Interviewees are asked to hang around during a two-form, two-stage drawn out interview process and to revisit bits of information already elicited. The 'you' language of the SIPF also actually discourages people from filling out forms for others, even though the push to enumerate people on a usual residents basis in the Northern Territory in fact relies on lots of people filling out SIPFs for absent others.

So I am not, in fact, convinced that in the Alice Springs town camps in 2001 at least, the IES was very successful at all. Indeed, it had to be modified half way through just in order to get a basic enumeration completed. In many ways it seemed that the special enumeration only improved on the standard enumeration in two respects - in being time-extended and interview-based. Another way of putting this would be to say that the 2001 Census might have been just as easily and successfully carried out in the Alice Springs town camps by sending in the interviewers armed with standard census household forms with two slight modifying instructions: enumerate all people who spent the night at the dwelling the previous night (rather than on 7 August), and complete multiple household forms for the one dwelling if there are more than six people present. What would have been 'special' about the Indigenous enumeration would have then simply been that it was time-extended and interview-based. But it would have been a much more standard census procedure in being an enumeration of people present, first and foremost, combined with the subsequent identification of absent usual residents. And it would have also been easier for people to fill in forms for others, as there would not have been identifiable SIPFs, with their personalised 'you' language.

This is perhaps a harsh judgment on the success of and need for the IES. But it is, to my mind, worth considering, if only in thinking seriously about how best to proceed in the future and what elements of the IES are indeed necessary, and which are unnecessary complications.

The alternative to reverting to a far more standardised census collection procedure, adapted only by time extension and interview processes, would seem to be to go for a far more thoroughly thought-through Indigenous enumeration process, with as much emphasis on changes in the content of what is asked as on changes in the process through which people 
are enumerated and information is collected. But even if such a more thoroughly thoughtthrough strategy were developed, I would argue strongly against any shift away from the standard census procedures of enumerating people where they are presently sleeping, rather than where they are usual residents. Enumerating those present stands as something of a bedrock principle for census administration. It is surely the most reliable way to count people and to find out from them, directly, their basic demographic and socioeconomic characteristics. When combined with sensible questioning about absent usual residents and, because of time extension, questioning about whether a person has been counted before recently, it surely provides still the best way to enumerate any population, no matter how mobile or how different its circumstances from broader community norms. 